\title{
Vaginal delivery after previous cesarean section in a rural West African hospital
}

\author{
C.N. Mock ${ }^{\mathrm{a}}$, L. Visser ${ }^{\mathrm{b}}$, T.E. Elkins ${ }^{\mathrm{c}}$ and J.B.Wilson ${ }^{\mathrm{d}}$ \\ "Department of Surgery, Rhode Island Hospital, Division of Biology of Medicine, Brown University. Providence, Rhode Island (USA),

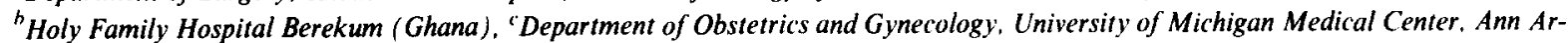 \\ bor, Michigan (USA) and 'Department of Obstetrics and Gynecology, Korle Bu Teaching Hospital, Accra (Ghana)
}

(Received December 15th, 1990)

(Revised and accepted January 23rd, 1991)

\begin{abstract}
Two hundred twenty women with prior cesarean section were delivered at our institution between January 1987 and February 1990. Vaginal delivery was achieved in 111 (66\%) of 169 patients given a trial of labor (TOL). Success of TOL correlated positively with the number of prior vaginal deliveries $(P<0.05)$ and inversely with the number of prior cesarean sections $(P<0.005)$. Maternal and fetal outcome were not significantly different between the TOL and non-TOL groups.
\end{abstract}

Keywords: Vaginal delivery; Previous cesarean section; Trial of labor.

\section{Introduction}

Trial of labor (TOL) for women with prior cesarean births has become an accepted alternative to routine repeat cesarean section (CS) in the industrialized world in hospitals where electronic fetal monitoring and capabilities for rapid cesarean section are available [9-15]. The application of the practice of TOL for women with prior cesarean sections to hospitals in the developing world has met with success in the few studies that have been published $[4-8,16,17]$. Vaginal delivery rates of $50-80 \%$ have been reported and the maternal and fetal outcomes have been similar to those of patients given routine repeat cesarean sections.

These studies have generally been from university hospitals in larger cities, some of which have facilities similar to hospitals in developed nations. No reports have addressed the issue of whether TOL is safe in smaller rural hospitals in the third world. The present study details the experience with TOL in our institution over a 3-year period.

\section{Materials and methods}

Prior to 1987 , repeat cesarean sections were routinely performed for women with a history of prior cesarean births at our hospital. Subsequently, selected patients were allowed trials of labor. The Holy Family Hospital is a 160 bed hospital serving a district of 1500 square miles with a population of 200000 . It is the referral center for 12 maternity homes staffed by nurse midwives and is the only location in the district where cesarean sections can be performed. The majority of vaginal deliveries are performed by nurse midwives, with physicians consulted for difficult cases. No electronic fetal monitoring or intrauterine pressure monitoring are avail- 
able. Monitoring is done by intermittent auscultation with a fetoscope. There is no blood bank, but typing and crossmatching can be performed and blood transfusions given as fresh whole blood, usually donated by the patients' relatives. A physician capable of performing a cesarean section is readily available $24 \mathrm{~h}$ per day and the hospital operating room has a cesarean section response capability from decision to incision of $30 \mathrm{~min}$. Anesthesia is by pentothal induction with ether maintenance for emergent cesarean sections and by spinal anesthesia with lidocaine for nonemergent cesarean sections.

Between January 1st, 1987 and February 28th, 1990, 220 patients with prior cesarean sections were delivered at the Holy Family Hospital and form the basis for this report. Excluded from this report were an additional eight patients who arrived after having been in unmonitored labor at home for more than $24 \mathrm{~h}$.

Statistical analysis of the results was performed by chi-square and the Student's $t$-test.

\section{Results}

\section{Vaginal delivery rates}

During the study period, 6691 women were delivered at the Holy Family Hospital. Of 220 women with prior cesarean section, $169(77 \%)$ were allowed a trial of labor. One hundred eleven of these patients delivered vaginally for a vaginal delivery rate of $66 \%$. Fifty-one patients underwent a repeat cesarean birth without a trial of labor, 30 presenting in early labor and 21 having elective antepartum cesarean sections. The overall vaginal delivery rate for the entire series was $51 \%$. Table 1 lists the indications for not allowing TOL. Patients with two prior cesarean sections were generally allowed a TOL in the latter part of the study period, but not initially. Patients with unknown type of uterine scar were allowed a trial of labor. Women with a definite history of a classical incision would not have been allowed a TOL, but none were encountered.
Table 1. Indications for no trial of labor

\begin{tabular}{lc}
\hline Indication & No. \\
\hline Elective group & 9 \\
Two prior CS & 3 \\
Three prior CS & 3 \\
Malpresentation & 1 \\
Twins & 1 \\
Prior uterine rupture & 4 \\
Physician's choice & 21 \\
Total & \\
Intrapartum group & 16 \\
Two prior CS & 1 \\
Three prior CS & 1 \\
Placenta previa & 1 \\
Failed induction & 11 \\
Physician's choice & 30 \\
Total &
\end{tabular}

Fifty-eight patients failed a TOL. Fortytwo $(72 \%)$ required a cesarean section for failure to progress, the remainder for fetal distress.

Patients undergoing TOL who had their initial cesarean section for breech and other malpresentations, placenta previa, or complications of twin gestation tended to have higher rates of vaginal delivery than those who had the first cesarean section for labor arrest or fetal distress (Table 2), but no difference reached statistical significance.

Table 2. Outcome versus indication for initial cesarean section in trial of labor group.

\begin{tabular}{lrrr}
\hline Indication & No. & \multicolumn{2}{c}{ Vaginal deliveries } \\
\cline { 3 - 4 } & & $n$ & $\%$ \\
\hline Fetal distress & 17 & 9 & 59 \\
Labor arrest & 72 & 44 & 61 \\
Malpresentation & 27 & 19 & 70 \\
Placenta previa & 13 & 11 & 85 \\
Twins & 5 & 5 & 100 \\
Unknown & 35 & 23 & 65 \\
Total & 169 & 111 & 66 \\
\hline
\end{tabular}


Table 3. Outcome versus number of prior vaginal deliveries in trial of labor group.

\begin{tabular}{lrrr}
\hline $\begin{array}{l}\text { No. of prior } \\
\text { vaginal deliveries }\end{array}$ & No. & \multicolumn{2}{c}{ Vaginal deliveries } \\
\cline { 2 - 4 } & & $n$ & $11 / 1$ \\
\hline None & 70 & 40 & 57 \\
1 & 38 & 25 & 66 \\
2 & 16 & 9 & 56 \\
3 or more & 45 & 37 & $82^{*}$ \\
Total & 169 & 111 & 66 \\
\hline
\end{tabular}

$\chi^{2}=8.36(\mathrm{df}=3), P<0.05$

In the TOL group, 102 of 143 patients (71\%) with one prior cesarean section had a successful TOL, whereas only 10 of 26 paticnts $(38 \%)$ with two prior cesarean sections delivered vaginally $\left(\chi^{2}=8.77, P<0.005\right)$. An increasing number of prior vaginal deliveries (Table 3 ) indicated a significantly increased likelihood of successful TOL $\left(\chi^{2}=\right.$ $8.36, P<0.05$ ). The sequence of prior vaginal deliveries and cesarean sections did not significantly alter the chance for success of TOL (Table 4).

Oxytocin was administered to 28 patients (17\% of TOL group), 16 patients receiving it for induction of labor and 12 for augmentation. When compared to patients not receiving oxytocin, the rate of cesarean sections rose from $33 \%$ to $43 \%$ and that of cesarean sec-

Table 4. Outcome versus sequence of prior deliveries in trial of labor group.

\begin{tabular}{|c|c|c|c|}
\hline \multirow[t]{2}{*}{ Sequence } & \multirow[t]{2}{*}{ No. } & \multicolumn{2}{|c|}{ Vaginal deliveries } \\
\hline & & $n$ & $\% / r$ \\
\hline $\begin{array}{l}\text { Vaginal delivery } \\
\text { before initial CS }\end{array}$ & 52 & 32 & 62 \\
\hline $\begin{array}{l}\text { Vaginal delivery } \\
\text { after initial CS }\end{array}$ & 20 & 15 & 75 \\
\hline $\begin{array}{l}\text { Vaginal delivery before } \\
\text { and after initial CS }\end{array}$ & 10 & 8 & 80 \\
\hline $\begin{array}{l}\text { Vaginal delivery, relation } \\
\text { to initial CS unknown }\end{array}$ & 17 & 16 & 94 \\
\hline
\end{tabular}

tions for fetal distress rose from $8 \%$ to $18 \%$. Neither of these differences were statistically significant. Eighteen deliveries were assisted by vacuum extraction.

Two women with twin gestation were allowed TOL, onc delivering vaginally. One woman with a twin gestation underwent an elective cesarean section.

\section{Maternal outcome}

There was one maternal death in the series. This G6 P5 30-year old, whose one cesarean section was on the last delivery for failure to progress, presented in early labor after 3 days of leaking vaginal fluid. She underwent an uneventful $5 \mathrm{~h}$ first stage and $30 \mathrm{~min}$ long second stage before delivering vaginally. The infant was asphyxiated and died shortly after delivery. The amniotic fluid was purulent. A retained placenta resulted in exsanguination. At the time of manual placenta removal, no uterine dehiscence or rupture was palpable. This death gave a maternal mortality rate of $0.6 \%$ in the TOL group, compared to an institutional maternal mortality rate of $0.9 \%$ for the study period.

Morbidity was not significantly different between the TOL and the non-TOL groups. One asymptomatic uterine dehiscence was noted at repeat cesarean section after a failed TOL. Two bladder injuries occurred during cesarean section in the non-TOL group, but both were easily repaired and recovered without sequelae. Sepsis, defined as persistent postoperative or postpartum fever requiring a course of antibiotics, occurred in three $(6 \%)$ non-TOL patients and one $(0.6 \%)$ TOL patient. A cervical laceration requiring repair was associated with a vacuum extraction.

\section{Fetal outcome}

There were 14 perinatal deaths in the series (Table 5). Among the seven stillbirths, six patients presented with no audible fetal heart sounds. All of these patients underwent TOL with four delivering vaginally. The other fetal death was preventable, occurring in a patient presenting with audible fetal heart tones. 
Table 5. Fetal outcome.

\begin{tabular}{|c|c|c|c|c|}
\hline & \multicolumn{2}{|c|}{$\begin{array}{l}\text { Trial of labor } \\
(N=171)^{\mathrm{a}}\end{array}$} & \multicolumn{2}{|c|}{$\begin{array}{l}\text { No trial } \\
\text { of labor } \\
(N=52)^{\text {a }}\end{array}$} \\
\hline & $n$ & $\%$ & $n$ & $\%$ \\
\hline \multicolumn{5}{|l|}{ Apgar $<7$} \\
\hline $1 \mathrm{~min}$ & 32 & 19 & 4 & $8^{*}$ \\
\hline $5 \mathrm{~min}$ & 10 & 6 & 1 & 2 \\
\hline \multicolumn{5}{|l|}{ Perinatal deaths } \\
\hline Fetal & 7 & 4 & 0 & 0 \\
\hline Neonatal & 6 & 4 & 1 & 2 \\
\hline $\begin{array}{l}\text { Corrected perinatal } \\
\text { mortality }\end{array}$ & 4 & 3 & 1 & 2 \\
\hline
\end{tabular}

ancludes twins.

$\chi^{2}=2.80, P<0.1,>0.05$.

Fetal demise occurred during a trial of labor augmented with oxytocin.

Six of the seven neonatal deaths occurred in the TOL group (Table 5). One fetus had multiple congenital anomalies and another was severely premature, weighing $1010 \mathrm{~g}$, a birthweight rarely compatible with life given the support facilities at our hospital. The other neonatal deaths were due to asphyxia in otherwise viable infants. Neither the neonatal mortality rate nor the corrected perinatal mortality rate (defined as perinatal deaths minus stillborns, infants with lethal congenital anomalies and severely premature infants) were significantly different for the TOL compared to the non-TOL group. These rates compare to an institutional neonatal death rate of $3.5 \%$ during the study period.

There was a trend toward a higher frequency of Apgar scores less than 7 in the TOL group compared to the group not given a TOL (Table 5). One minute Apgar scores of less than 7 occurred in $32(19 \%)$ of the TOL infants and in four $(8 \%)$ of the non-TOL group $\left(\chi^{2}=2.80, P<0.1,>0.05\right)$. Apgar scores at $5 \mathrm{~min}$ were not statistically different between the two groups.

The birthweight in the vaginally delivered group (mean of $2900 \mathrm{~g}$, range $900-4010 \mathrm{~g}$ ) was lower than that for the failed TOL group (mean of $3110 \mathrm{~g}$, range $1850-4210 \mathrm{~g})(P<$ 0.01 ). Furthermore, the birthweight in the group not given a trial of labor (mean of 2790 $\mathrm{g}$, range $1710-3940 \mathrm{~g}$ ) was lower than that for the TOL group as a whole (mean of 2970 $\mathrm{g}$, range $900-4210 \mathrm{~g})(P<0.05)$.

There was a trend toward a higher percentage of low hirthweight infants in the elective antepartum cesarean section group compared to the TOL group. Six infants $(29 \%)$ in the elective antepartum cesarean section group weighed less than $2500 \mathrm{~g}$ compared to 20 $(12 \%)$ in the TOL group $\left(\chi^{2}=2.83, P<0.1\right.$, $>0.05$ ).

The use of oxytocin did not significantly affect the neonatal death rate (Table 6) and was not associated with any uterine dehiscences or ruptures. There was a trend toward more frequent Apgar scores less than 7 at 1 min, but not at $5 \mathrm{~min}$, in the group receiving oxytocin compared to the group not receiving it (Table 6). Duration of labor longer than $12 \mathrm{~h}$ did not adversely affect the fetal outcome compared to the group delivered with less than $12 \mathrm{~h}$ of labor (Table 7).

Table 6. Use of oxytocin versus fetal outcome in trial of labor group.

\begin{tabular}{|c|c|c|c|c|}
\hline & \multicolumn{2}{|c|}{$\begin{array}{l}\text { Oxytocin group } \\
(N=29)^{\mathrm{a}}\end{array}$} & \multicolumn{2}{|c|}{$\begin{array}{l}\text { No oxytocin } \\
\text { group } \\
(N=149)^{\mathrm{a}}\end{array}$} \\
\hline & $n$ & $\%$ & $n$ & $10 / 11$ \\
\hline \multicolumn{5}{|l|}{ Apgar $<7$} \\
\hline $1 \mathrm{~min}$ & 9 & 31 & 23 & $16^{*}$ \\
\hline $5 \mathrm{~min}$ & 2 & 7 & 8 & 6 \\
\hline \multicolumn{5}{|l|}{ Perinatal deaths } \\
\hline Fetal & 5 & 17 & 2 & 1 \\
\hline Neonatal & 1 & 3 & 5 & 3 \\
\hline $\begin{array}{l}\text { Corrected neonatal } \\
\text { mortality }\end{array}$ & 0 & 0 & 4 & 3 \\
\hline
\end{tabular}

Includes one set of twins in each group.

${ }^{*} \chi^{2}=3.38, P<0.1,>0.05$. 
Table 7. Duration of labor versus outcome in trial of labor group.

\begin{tabular}{|c|c|c|c|c|}
\hline & \multicolumn{2}{|c|}{$\begin{array}{l}>12 \mathrm{~h} \\
(N=39)\end{array}$} & \multicolumn{2}{|c|}{$\begin{array}{l}<12 \mathrm{~h} \\
(N=130)\end{array}$} \\
\hline & $n$ & $\%$ & $n$ & $\%$ \\
\hline Cesarean sections & 15 & 38 & 43 & 33 \\
\hline \multicolumn{5}{|l|}{ Apgar $<7$} \\
\hline $1 \mathrm{~min}$ & 10 & 26 & 22 & 17 \\
\hline $5 \mathrm{~min}$ & 3 & 8 & 7 & 5 \\
\hline \multicolumn{5}{|l|}{ Perinatal deaths } \\
\hline Fetal & 2 & 5 & 5 & 4 \\
\hline Neonatal & 1 & 3 & 5 & 4 \\
\hline
\end{tabular}

\section{Excluded cases}

The outcome of the eight patients with prior cesarean births who presented to the hospital after $\geq 24 \mathrm{~h}$ of unmonitored labor at home was dismal. Five women delivered vaginally, one with a healthy infant, two with neonatal deaths due to asphyxia, and two with stillbirths. One of the latter had a ruptured uterus, which was detected after delivery and was repaired without complication via laparotomy.

Three women underwent cesarean section, one delivering a live infant. One was found to have a ruptured uterus with the dead fetus extruding into the peritoneal cavity. The ruptured uterus was repaired without complication. The last woman presented after 3 days of obstructed labor with ruptured membranes. A stillborn infant was delivered via cesarean section at which time marked chorioamnionitis was found. The woman expired from sepsis on the fifth postoperative day.

\section{Discussion}

Trial of labor following previous cesarean section has seldom been championed in Africa's developing countries. Numerous reasons are cited for this. African women generally have a more narrow pelvis by clinical and radiologic dimensions [2,3]. Therefore, less optimism is held for vaginal delivery following a previous cesarean section, especially if any evidence for cephalopelvic disproportion existed in past deliveries. The narrow pelvic inlet in African women causes a delayed entry of the fetal vertex into the pelvic inlet. This may result in a quick decision to resort to cesarean section in African populations and makes waiting for a trial of labor less likely. There is also a paucity of fetal monitoring instrumentation and uterine pressure monitors, both of which have been shown to be helpful in the early detection of uterine rupture $[10,11,13]$. Widespread use of these monitoring techniques has led to a general acceptance of TOL after cesarean section in developed countries after one $[10-13,15]$ or even more cesarean sections [14]. Finally, blood banking facilities are often limited in developing countries, making the successful management of uterine rupture very difficult. As this study shows, other problems may occur after cesarean section, including placenta accreta and postpartum hemorrhage, that require blood transfusion to prevent maternal death. For these reasons, few studies about TOL after cesarean section have been reported from sub-Saharan Africa, where the above factors are especially notable. All of these studies are from major teaching hospitals $[5,6,8]$.

However, there are compelling reasons to consider a trial of labor in selected patients, even in a rural hospital setting. General shortages of supplies, instruments, blood products, and trained surgeons make vaginal deliveries much more cost efficient than cesarean deliveries. Routine repeat cesarean deliveries for all patients may simply be impossible with current supply shortages in many areas of the developing world.

Series reported from the developing world demonstrate both the efficacy and the safety of TOL in patients with prior cesarean section. Most of the standards set for safe TOL in the developed world [1] can be met even in 
rural hospitals. These include $24 \mathrm{~h}$ availability of a physician capable of evaluating labor and performing a cesarean section, operating room response time of $30 \mathrm{~min}$, and blood transfusion capability. Only electronic fetal monitoring is not commonly available.

This series's vaginal delivery rate of $66 \%$ is within the $50-80 \%$ range reported by other series in the developing world $[4-8,16,17]$. The likelihood of successful TOL increased with prior history of one compared to two prior cesarean sections and with incrcased number of prior vaginal deliveries (Table 3) [7]. There was also a tendency toward increased success of TOL if the indication for the first cesarean section was non-recurrent, such as twins or malpresentation, rather than cephalopelvic disproportion or failure to progress (Table 2) $[5,6,17]$. Fetal distress would be expected to be a nonrecurring indication, but was associated with a lower vaginal delivery rate (Table 2). There may be overlap between categories in that some of the fetal distress may have occurred because of prolonged labor [6].

Fears about maternal safety had not been born out. Although uterine rupture rates of $0.7-4.9 \%[5-8,16,17]$ have been reported, maternal mortality and other morbidity have not been elevated above that of patients undergoing routine repeat cesarean section [4-6,8,17]. Although there was one maternal death in the TOL group in the current series, this was not related to a uterine rupture. Furthermore, the maternal mortality rate in the TOL group was similar to that for the hospital as a whole. Only one asymptomatic uterine dehiscence occurred in the TOL group and no symptomatic ruptures occurred in any TOL patients undergoing monitored labor in the hospital.

Concerns about fetal safety, likewise, have not materialized. Apgar scores were not significantly different for the TOL infants compared to the non-TOL group (Table 5). There was no change in preventable neonatal mortality when the TOL group, the non-TOL group, and the hospital as a whole were compared. Similar fetal outcomes are reported by others [4-6,8]. Dhall et al. [7] found equal perinatal mortality rates for failed TOL and elective repeat cesarean section, but lessened mortality with successful vaginal delivery.

Although the difference was not statistically significant, there was a trend toward a higher frequency of low birthweight infants in the elective cesarean section group $(29 \%)$ compared to the TOL group (12\%). The increased number of low birthweight infants in the elective cesarean section group could be due to iatrogenic prematurity secondary to inability to accurately assess gestational age in our setting. However, this did not lead to any increase in neonatal mortality from prematurity.

Wadhawan and Narrone [17] found increased fetal asphyxia from labors lasting greater than $12 \mathrm{~h}$. In the current study, both the neonatal death rate and the Apgar scores were unchanged with duration of labor less than $12 \mathrm{~h}$ compared to greater than $12 \mathrm{~h}$ (Table 7), indicating that time for adequate TOL can be allowed.

Use of oxytocin in patients with prior cesaren section has been found to be safe in the carefully monitored settings of the industrialized world. Experience in the developing world has been mixed. Dejong [5] and DeMuylder [6] have used it rarely. Singh et al. [16] report an increased scar rupture rate with its use. However, Dhall et al. [7] and Egwuatu and Ezeh [8] have used it safely. In this series, the neonatal mortality rate and the corrected perinatal mortality rate were not significantly altered by the use of oxytocin (Table 6). However, one preventable fetal death was associated with its use. While no firm conclusions can be drawn about the use of oxytocin because of the small number of patients in whom it was used, one preventable fetal death out of 28 deliveries is notable. Extreme caution should be exercised with the use of oxytocin in trials of labor in patients with prior cesarean sections in the setting of a rural third world hospital.

Perhaps the most compelling reason for allowing TOL in the developing world, and especially in Africa, is the intense aversion 
seen among many in Africa to surgical deliveries per se. This desire to avoid repeat surgery may lead patients with prior cesarean sections to labor at home, in an unmonitored environment, far beyond any recommended time, at great risk to both mother and fetus $[6,8]$. In this study, the eight patients who delayed coming to the hospitals suffered six perinatal deaths, two uterine ruptures and one maternal death. Perhaps, these results could have been altered if the patients had presented for a monitored trial of labor. Increased use of trial of labor for patients with prior cesarean sections might induce such patients to present earlier to the hospital for more closely monitored labor.

\section{Conclusion}

This study shows that vaginal delivery after cesarean delivery can be achieved in a reasonable fashion in suitable medical centers, even when these centers are in rural sub-Saharan Africa. The minimum conditions for trials of labor in such locations include staffing of the labor rooms with nurses or midwives capable of accurately auscultating fetal heart tones and of following the progress of labor, $24 \mathrm{~h}$ availability of a physician capable of evaluating labor and performing a cesarean section, availability of blood transfusions and prompt operating room response capability for cesarean section. In the current study, $66 \%$ of women given a trial of labor delivered vaginally. Maternal and fetal mortality and morbidity were not significantly different for patients given a trial of labor compared to those who were delivered by routine cesarean section without trial of labor or to other obstetrical patients in the same location. The limiting of trial of labor candidates to persons with known lower segment scars must be considered as further protocol trials are attempted.

\section{References}

1 Anonymous: Trial of labor and vaginal delivery following previous cesarean birth: previous recommendations (1982) and current recommendations (1985). ACOG Newslett 31: 11, 1987.

2 Bernard RM: The shape and size of the female pelvis. Edinburgh Med J 59: 1, 1952 (Trans Edinburgh Obstet Soc).

3 Briggs ND: Engagement of the fetal head in the negro primigravida. Br J Obstet Gynecol 88: 1086, 1981.

4 Chi I, Saifuddin AB, Gunatilake DE, Wallace SL: Deliveries after cesarean birth in two Asian university hospitals. Int J Gynecol Obstet 2l: 11, 1983.

5 DeJong P: Trial of labor following cesarean section - a study of 212 patients. Int J Gynecol Obstet 24: 405, 1987.

6 DeMuylder X: Vaginal delivery after cesarean section: is it safe in a developing country. Aust NZ J Obstet Gynecol 28: 99, 1988.

7 Dhall K, Mittal SC, Grover V, Dhall GI: Childbirth following primary cesarean section: evaluation of a scoring system. Int J Gynecol Obstet 25: 199, 1987.

8 Egwuatu VE, Ezeh IOU: Vaginal delivery in Nigerian women after a previous cesarean section. Int J Gynecol Obstet 32: 1, 1990.

9 Finley BE, Gibbs CE: Emergent cesarean delivery in patients undergoing a trial of labor with a transverse lowersegment scar. Am J Obstet Gynecol 155: 936, 1986.

10 Jarrell MA, Ashmeed GG, Mann LI: Vaginal delivery after cesarean section: a five year study. Obstet Gynecol 65 : 628, 1985.

11 Levin JP, Stephens RJ, Miodovnik M, Barden TP: Vaginal delivery in patients with prior cesarean section. Obstet Gynecol 59: 135, 1982.

12 Martin JN, Harris BA, Huddlastain JF et al: Vaginal delivery following previous cesarean birth. Am J Obstet Gynecol 146: 255, 1984.

13 Molloy BG, Shiel O, Duignan NM: Delivery after cesarean section: a review of 2,176 consecutive cases. $\mathrm{Br}$ Med J 294: 1645, 1987.

14 Phelan JP, Ahn MO, Diaz F, Brar HS, Rodriguez, H: Twice a cesarean, always a cesarean? Obstet Gynecol 73: 161. 1989.

15 Phelan JP, Clark SL, Diaz F, Paul RH: Vaginal birth after cesarean. Am J Obstet Gynecol 157: 1510, 1987.

16 Singh TKC, Barman SD, Gupta AN: Study of vaginal delivery in patients with one previous lower segment cesarean section. Aust NZ J Obstet Gynecol 26: 245, 1986.

17 Wadhawan S, Narone JN: Outcome of labor following previous cesarean section. Int J Gynecol Obstet 21: 7 , 1983.

Address for reprints:

C.N. Mock

Department of Surgery

APC-143, Room 143

Rhode Island Hospital

593 Eddy Street

Providence, RI 02903, USA 